\title{
Carcinofibroma of the corpus uteri
}

INSERM

\section{Source}

INSERM. (1999). Orphanet: an online rare disease and orphan drug data base.

Carcinofibroma of the corpus uteri. ORPHA:213605

Carcinofibroma of the corpus uteri is an extremely rare subtype of mixed müllerian tumor characterized by the presence of a uterine neoplasm which simuntaneously presents a malignant epithelial component (carcinomatous glands) and a benign mesenchymal component. Clinical presentation typically includes dysfunctional vaginal bleeding, abnormal vaginal discharge and/or lower abdominal pain. 